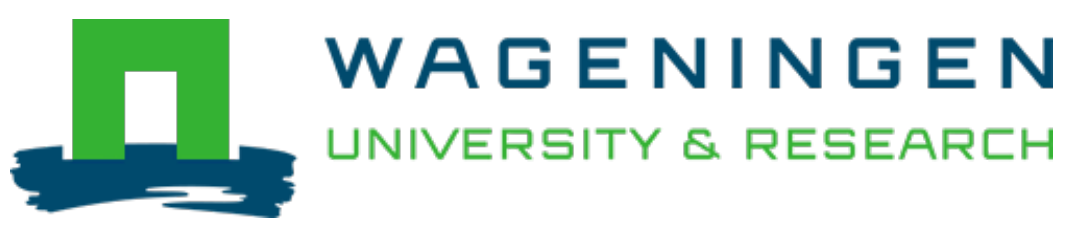

\title{
Development of a standard test for dough-making properties of oat cultivars
}

\author{
Journal of Cereal Science
}

Londono Cardona, D.M.; Smulders, M.J.M.; Visser, R.G.F.; Gilissen, L.J.W.J.; Hamer, R.J. https://doi.org/10.1016/j.jcs.2013.10.007

This article is made publicly available in the institutional repository of Wageningen University and Research, under the terms of article $25 \mathrm{fa}$ of the Dutch Copyright Act, also known as the Amendment Taverne. This has been done with explicit consent by the author.

Article $25 \mathrm{fa}$ states that the author of a short scientific work funded either wholly or partially by Dutch public funds is entitled to make that work publicly available for no consideration following a reasonable period of time after the work was first published, provided that clear reference is made to the source of the first publication of the work.

This publication is distributed under The Association of Universities in the Netherlands (VSNU) 'Article $25 \mathrm{fa}$ implementation' project. In this project research outputs of researchers employed by Dutch Universities that comply with the legal requirements of Article $25 \mathrm{fa}$ of the Dutch Copyright Act are distributed online and free of cost or other barriers in institutional repositories. Research outputs are distributed six months after their first online publication in the original published version and with proper attribution to the source of the original publication.

You are permitted to download and use the publication for personal purposes. All rights remain with the author(s) and / or copyright owner(s) of this work. Any use of the publication or parts of it other than authorised under article $25 \mathrm{fa}$ of the Dutch Copyright act is prohibited. Wageningen University \& Research and the author(s) of this publication shall not be held responsible or liable for any damages resulting from your (re)use of this publication.

For questions regarding the public availability of this article please contact openscience.library@wur.nl 


\title{
Development of a standard test for dough-making properties of oat cultivars
}

\author{
Diana M. Londono ${ }^{a}$, Marinus J.M. Smulders ${ }^{\mathrm{a}, \mathrm{c}, *}$, Richard G.F. Visser ${ }^{\mathrm{a}}$, \\ Luud J.W.J. Gilissen ${ }^{b, c}$, Rob J. Hamer ${ }^{\mathrm{d}}$ \\ ${ }^{a}$ Wageningen UR Plant Breeding, P.O. Box 386, NL-6700 AJ Wageningen, The Netherlands \\ ${ }^{\mathrm{b}}$ Plant Research International, Wageningen UR, P.O. Box 16, NL-6700 AA Wageningen, The Netherlands \\ ${ }^{\mathrm{C}}$ Allergy Consortium Wageningen, P.O. Box 16, NL-6700 AA Wageningen, The Netherlands \\ ${ }^{\mathrm{d}}$ Wageningen UR Food Chemistry, P.O. Box 8129, NL-6700 EV Wageningen, The Netherlands
}

\section{A R T I C L E I N F O}

\section{Article history:}

Received 7 May 2013

Received in revised form

11 October 2013

Accepted 15 October 2013

\section{Keywords:}

Oat flour

Oat bread

Gluten-free bread

\begin{abstract}
A B S T R A C T
Bread is consumed all over the world. However, so far, production of large volume bread is only possible with wheat. Alternatives, such as oats, are less suitable but this is partly due to the lack of knowledge about their functionality for other purposes than porridge, which is their most common use. Existing standard tests for the dough making characteristics of wheat flour are not suitable for oat flour, hampering research to optimize oats for bread-making purposes. We therefore set out to develop a test to evaluate oat in relation to mixing and dough making properties using wheat as a model. It was possible to reproduce the profile of various qualities of wheat flour using mixtures of oat flour and gluten in different proportions. Our standard test was based on a dough system composed of $87.2 \%$ oat flour and $12.8 \%$ gluten and it presented similar properties to a wheat flour with regard to resistance to extension. This dough system was sensitive and reliable (coefficient of variation lower than $10 \%$ ) for detecting differences among oat cultivars, and it can be used to screen oat varieties and individual oat components in relation to relevant properties for bread-making purposes.
\end{abstract}

(c) 2013 Published by Elsevier Ltd.

\section{Introduction}

Bread is an important staple especially in European countries with wheat (Triticum aestivum) bread being most popular among consumers. There is an increasing demand for new products for different target groups that should meet different quality criteria related to texture, taste, nutrition, and health. Oat is an interesting alternative for people with celiac disease (Pulido et al., 2009; Londono et al., 2013), or people who for example like to benefit from the health -related compounds present in oat (Butt et al., 2008).

The inclusion of oat in the daily diet is encouraged because it contains components that have been associated with health benefits, notably beta-glucans, that help to decrease cholesterol and glucose in the blood (Butt et al., 2008; Jenkins et al., 2002). High blood cholesterol is a major risk factor for coronary artery disease

\footnotetext{
* Corresponding author. Wageningen UR Plant Breeding, P.O. Box 386, NL-6700 AJ Wageningen, The Netherlands. Tel.: +31 317480840.

E-mail addresses: diana.londono@wur.nl (D.M. Londono), rene.smulders@ wur.nl (M.J.M. Smulders), richard.visser@wur.nl (R.G.F. Visser), luud.gilissen@ wur.nl (L.J.W.J. Gilissen), Rob.hamer@wur.nl (R.J. Hamer).
}

which is one of the main causes of death in Western countries (Butt et al., 2008). Beta-glucans are considered as a functional component for prevention of cardiovascular diseases and of type II diabetes (Jenkins et al., 2002).

People that suffer from celiac disease, a chronic disorder caused by ingestion of gluten proteins that affects about $1 \%$ of the Western population, should stick to a long-life gluten-free diet. But gluten free breads - and, for that matter, gluten free products in general-, have an inferior quality compared to those made of wheat flour (Hager et al., 2012). In a comparison of different gluten-free formulations, loaves made of wholegrain oat flour presented similar specific volume to loaves made of wholegrain wheat flour, the loaf specific volumes were 2.40 for oat bread and $2.62 \mathrm{ml} / \mathrm{g}$ for wheat bread (Hager et al., 2012). However, despite their similarity, these volumes are considered of inferior quality in comparison to standard white wheat breads, which have specific volumes between 3.5 and $4 \mathrm{~mL} / \mathrm{g}$ (Belitz et al., 2004).

Gluten-free bread making is normally based on low viscosity systems known as batter systems. They account for a water addition ranging between 95 and 120\% w/w (Hager et al., 2012; Huttner et al., 2009). This approach has been used to test bread-making performance of commercial oat flours and oat cultivars, and differences 
have been reported using the same formulation for all of them: $100 \%$ oat flour, $120 \%$ water, $1.75 \%$ salt, $1 \%$ sugar, and $2 \%$ dried yeast (Hüttner et al., 2010a,b; Hüttner et al., 2011). The largest differences among oat cultivars regarding bread-making were observed in crumb texture while no significant differences in loaf specific volume occurred (about $1.5 \mathrm{ml} / \mathrm{g}$ ). Additionally, various technologies have been tested to improve quality of oat bread by treating the batters with high pressure (Huttner et al., 2009), adding enzymes (Renzetti and Arendt, 2009; Renzetti et al., 2009), hydrocolloids (Huttner et al., 2010a,b), or bacteria (Moore et al., 2007).

The baking quality of wheat is mainly determined by gluten content and its composition (Bushuk, 1998). Gluten proteins confer the unique viscoelastic properties to wheat dough which are essential for gas retention. Of all gluten proteins the high molecular weight (HMW) glutenins contribute most to the elastic properties of wheat dough and to the loaf volume (Bushuk, 1998). The lower quality of oat bread compared to wheat bread has been mainly attributed to the absence of gluten proteins in oat. Normally, when people use the term 'oat bread', they refer to composite breads made of mixtures of oat meal and wheat flour in various proportions. So far, the maximum amount of oat meal that has been used in a composite oat/wheat bread without compromising texture is $51 \%$ together with an adjustment of the formulation and the baking process (Flander et al., 2007).

From a practical point of view, it would be more convenient for bakers to use a dough system instead of a batter system to make oat bread because batters are sticky and difficult to handle, but also to avoid the use of thickening agents on which batter systems rely because they are costly. There is however a gap of knowledge concerning the relevant functional aspects of oat flour and the technology required for making oat bread. There are no standard parameters to test oat flours using dough systems that can fulfil the same functions as the parameters that exist for wheat flour. The Farinograph and extensibility parameters to test bread quality of wheat flours are well defined, but cannot be used as such for oat flour. Therefore, we aimed to develop a standardised dough system to test the intrinsic technological properties of oat cultivars and to be able to study the functionality of different oat components on the bread-making properties. Our approach was based on replacement of a fraction of oat flour with vital gluten to determine if it was possible to reconstruct, partly or completely, typical wheatlike properties, using the maximum amount possible of oat flour as basis. The standard system proposed does not reflect the final oat bread aimed for with respect to optimal quality, but only forms a first step towards good quality oat bread. The standard system simply serves an analytical purpose in order to fill the knowledge gap regarding the effects of components of oat.

\section{Materials and methods}

\subsection{Flours}

For the experiments, we used commercial oat meal (De Vlijt, Wageningen, the Netherlands), wheat flour - which we will refer to as wheat flour " $C$ "-, and its gluten fraction (provided by Cargill, the Netherlands), and commercial wheat Patent flour (C1000, the Netherlands). As the texture of oat meal was visibly coarser than the texture of wheat flours, the size of the particles in $50 \mathrm{~g}$ of oat meal was characterized using a series of sieves of $0.500,0.300$, $0.250,0.180,0.150$, and $0.071 \mathrm{~mm}$ opening. We decided to use only the fraction that passed through the $0.250 \mathrm{~mm}$ sieve to eliminate possible detrimental effects of large particles on the gluten network (Noort et al., 2010). This fine fraction was packed in plastic bags, sealed and stored in the freezer until use. This fine fraction $(<0.250 \mathrm{~mm})$ is what we refer to as oat flour in this study.
Moisture content of oat meal, oat flour, and wheat flour was calculated using the AACC method 44-15A. Nitrogen was determined by combustion (AACC approved method 46-30) using a NA 210 nitrogen and protein analyser (ThermoQuest, Ronado, Italy) to calculate the protein content, using a factor of 6.25. Total starch was quantified using the AACC method 76-13, and $\beta$-glucan content by the AACC method 32-23.

Once the standard test was developed using the sieved fraction of commercial oat meal, grains of 10 oat cultivars (DLO, the Netherlands) were put in a $0.5 \mathrm{~m}^{3}$ steel container to undergo the kilning process. First, a grain layer of three $\mathrm{cm}$ was placed in the container and steamed for $3 \mathrm{~min}$ at $100^{\circ} \mathrm{C}$. Then, the grains were let cool down for $30 \mathrm{~min}$ and placed in a drying oven at $85{ }^{\circ} \mathrm{C}$ overnight. The grains were milled at $8000 \mathrm{rpm}$ (Hosokawa Alpine D86199, Augsburg), and sieved in the same way described for oat meal to remove the bran particles. The fraction that passed through the $<0.250 \mathrm{~mm}$ sieve was used to compare their extensibility properties to test the sensitivity of the standard dough system to detect differences. The composition of the oat varieties is presented as Supporting information (S1).

\subsection{Making a dough system}

We prepared dough using pure oat flour and mixtures of oat flour and vital gluten in different proportions in a total weight of $10 \mathrm{~g}$ (14\% moisture). In total, seven flours were used to make dough: pure oat flour and mixtures in which a fraction of oat flour was replaced with $0.08,0.16,0.32,0.64,1.28$, and $2.56 \mathrm{~g}$ of gluten. The wheat flour " $\mathrm{C}$ " that was used as source to extract the gluten was used as control for its functionality in the mixtures; dough made of commercial wheat Patent flour was included just for comparison. $2 \%$ (mixture basis) $\mathrm{NaCl}$ was added to all flours to prepare a dough according to the method 54-21.

A Micro-Farinograph (Brabender instruments, Mod.-No. 8110) was used to determine the amount of water that each flour required to get a consistency of $500 \mathrm{BU}$, which is the standard consistency to test quality of wheat flour, and to establish the mixing time required to reach the peak consistency (dough development time). First, we determined the water absorption that each of the flours required. Then, we proceeded to prepare the dough using the Micro-Farinograph. The dough was allowed to relax in a plastic container within an incubator for $20 \mathrm{~min}$ at $30^{\circ} \mathrm{C}$ and a constant relative humidity of $85 \%$. After relaxation the dough was homogenized by hand and pressed between two oiled grooved forms to make dough strips. These strips were let to relax again for $40 \mathrm{~min}$ within the grooved bases in a plastic container at $24{ }^{\circ} \mathrm{C}$ and constant relative humidity. Subsequently, its maximum extensibility $(\mathrm{mm})$ and resistance to extension $(\mathrm{g})$ were measured using a Texture Analyser fitted with the SMS/Kieffer Extensibility Rig (Stable Micro systems). The standard settings for wheat flour were used according to instructions of manufacturer:

Mode: Measure force in tension

Option: Return to start

Pre-test speed: $2.0 \mathrm{~mm} / \mathrm{s}$

Test speed: $3.3 \mathrm{~mm} / \mathrm{s}$

Post-test speed: $10.0 \mathrm{~mm} / \mathrm{s}$

Distance: $120 \mathrm{~mm}$

Trigger force: $5 \mathrm{~g}$

Data acquisition rate: 200 pps

\subsection{Standardisation of consistency and mixing time}

Initially we selected a mixture of oat flour and gluten that presented intermediate values of maximum extensibility, resistance to 
extension, and strain hardening in comparison to wheat flour at a consistency of $500 \mathrm{BU}$, used as standard consistency to test wheat flours. Low variation between measurements was also a criterion for the selection. Subsequently, that system was used to prepare dough at different consistencies (500, 700, and $900 \mathrm{BU})$ to see if there was an effect of consistency on the extensibility parameters. Finally, the effect of mixing time on extensibility parameters of a selected dough system was tested after mixing for 2, 3, 4, and $5 \mathrm{~min}$.

\subsection{Strain hardening}

Strain hardening defines the level of elastic or plastic behaviour of a material. We calculated the strain hardening of the dough by fitting the extensibility data obtained with the Texture Analyser (Stable Micro systems) to the stress-strain curve to the formula described by Dunnewind et al. (2003), between the measured strain-range of $20-95 \%$. The sample volume extended was assumed as constant and banding distance was neglected. The formula used to calculate strain hardening was:

$\sigma=k \cdot e^{\varepsilon \cdot n}$

Stress $(\sigma)$ and Henky-strain $(\varepsilon)$ were determined at fracture. The coefficient $n$ is the strain hardening index. Regression coefficient $\left(R^{2}\right)$ was calculated for each sample.

\section{Results}

\subsection{Characterization of flours}

Commercial oat meal had a coarser texture than wheat flour; only $31.4 \%$ (weight basis) passed through the $0.250 \mathrm{~mm}$ sieve (Table 1). This fraction is referred to as 'oat flour' in this article and was used to prepare the flour mixtures to perform the experiments. The composition of oat meal (and its respective fractions), wheat flour and vital gluten are given in Table 1 . Complete oat meal and its sieved 'oat flour' fraction differed considerably: oat meal had 30\% more protein, $78 \%$ more beta-glucan and $14 \%$ less starch than its sieved 'oat flour' fraction. The fat content was the same. The medium fraction $(0.250-0.500 \mathrm{~mm})$ had the highest content of fat.

\subsection{Oat dough system at $500 \mathrm{BU}$}

The farinograms of pure oat flour and of the mixtures made by replacing $0.08,0.16$, and $0.32 \mathrm{~g}$ of oat flour with gluten (in $10 \mathrm{~g}, 14 \%$ moisture), showed an initial short peak consistency that declined rapidly and a narrow fluctuation that looks like a line. This peak consistency is related to hydration but dough development does not occur (Fig. 1a). In contrast, significant improvements of dough strength, observed as a longer peak time and as a wider amplitude of the band in the farinograms, were obtained when replacing 0.64 , 1.28 , and $2.56 \mathrm{~g}$ oat flour with gluten; the dough development of oat flour improved gradually with the increase of gluten at the mentioned amounts (Fig 1b, c d). The water absorption of flour mixtures increased proportionally to gluten content, from $5.77 \mathrm{ml}$ in the mixture containing $0.08 \mathrm{~g}$ gluten to $7.9 \mathrm{ml}$ in the mixture containing $2.56 \mathrm{~g}$ gluten.

The wheat flour ' $C$ ', used to extract the gluten used in the mixtures, absorbed $5.46 \mathrm{ml}$ water/10 $\mathrm{g}$ flour and the commercial wheat Patent flour absorbed $6.7 \mathrm{ml} / 10 \mathrm{~g}$ flour to reach a consistency of 500 BU. Farinogram consistency of these two wheat flours became stable around $500 \mathrm{BU}$, while consistency of oat flour mixtures, independently of their gluten content, dropped off to $300 \mathrm{BU}$ (Fig. 1).

\subsection{Extensibility properties of oat dough at $500 \mathrm{BU}$}

Maximum resistance to extension $(g)$ and maximum extensibility $(\mathrm{mm})$ of the dough at $500 \mathrm{BU}$ were exponentially proportional to the gluten content in the flour mixtures. There was no difference in extensibility properties between pure oat flour and oat flour mixtures containing $0.08,0.16$, and $0.32 \mathrm{~g}$ gluten $/ 10 \mathrm{~g}$, the strain hardening values of these dough were below one (Table 2). In contrast, clear improvements were observed in flour mixtures containing $0.64,1.28$, and $2.56 \mathrm{~g}$ gluten $/ 10 \mathrm{~g}$, which is consistent with the improvement on dough development observed in the Farinograph test at the same levels of gluten. At these levels of gluten the dough had a strain hardening of $1.29,1.22$, and 1.4 , respectively (Table 2 ).

Values for maximum resistance to extension and maximum distance of the wheat flour ' $\mathrm{C}$ ' and of commercial wheat Patent flour fell between the values obtained for oat flour mixtures containing 1.28 and $2.56 \mathrm{~g}$ gluten/10 $\mathrm{g}$ (Fig. 2). The values of strain hardening for wheat flour ' $\mathrm{C}$ ' and wheat Patent flour were 1.39 and 1.35 , respectively. These results suggest that reconstruction of technological properties of wheat flour using oat flour as basis and gluten is feasible. Because our purpose was to develop a sensitive test system, it should not contain too much gluten since this could mask any differences that may exist among oat cultivars. We therefore selected the system composed of $8.72 \mathrm{~g}$ oat flour and $1.28 \mathrm{~g}$ gluten, the coefficients of variation for the extensibility test were 6.7 and 9.6\% for maximum resistance to extension and distance, respectively. This system had a similar behaviour to a wheat flour suitable to be used in pastry applications (Fig. 2).

\subsection{Effect of consistency on extensibility properties}

The selected system, composed of $8.72 \mathrm{~g}$ oat flour and $1.28 \mathrm{~g}$ gluten, was used to prepare dough in the Farinograph at different

Table 1

Composition of oat meal and its respective fractions, wheat flours and vital gluten (as is), used to develop a standard oat dough system.

\begin{tabular}{|c|c|c|c|c|c|c|c|}
\hline \multirow[t]{2}{*}{ Material } & \multirow{2}{*}{$\begin{array}{l}\text { Proportion of oat } \\
\text { meal (weight) \% }\end{array}$} & \multicolumn{6}{|c|}{ Moisture composition (mg/100 mg) mass } \\
\hline & & $\%$ & Starch & Protein & B-glucan & Fat & $\%$ \\
\hline Oat meal: & 100 & 6.98 & 61.75 & 12.50 & 5.54 & 11.05 & 97.82 \\
\hline Fraction $>0.500 \mathrm{~mm}$ & 44.41 & 11.46 & 44.68 & 16.98 & 8.35 & 11.90 & 93.37 \\
\hline Fraction $0.250-0.500 \mathrm{~mm}$ & 15.16 & 12.78 & 51.92 & 22.20 & 0.40 & 13.91 & 101.22 \\
\hline Fraction $<0.250 \mathrm{~mm}^{\mathrm{a}}$ & 31.36 & 16.18 & 72.12 & 8.70 & 1.20 & 11.30 & 109.50 \\
\hline Not recovered & 9.07 & - & - & - & - & - & - \\
\hline Wheat flour ' $C$ ' & - & 14.9 & 70.29 & 10.4 & 0.2 & 4.82 & 100.61 \\
\hline Wheat Patent Flour ${ }^{\mathrm{b}}$ & - & 11.2 & $70.3(70.9)$ & $10.6(11)$ & 0.2 & $4.72(1.0)$ & 97.02 \\
\hline Vital gluten & - & 2.50 & 4.88 & 80 & - & 10.5 & 97.88 \\
\hline
\end{tabular}

a Fraction used to perform the experiments and what we refer to as 'oat flour'.

b Composition of commercial wheat Patent flour as listed on the packaging is shown between brackets. 


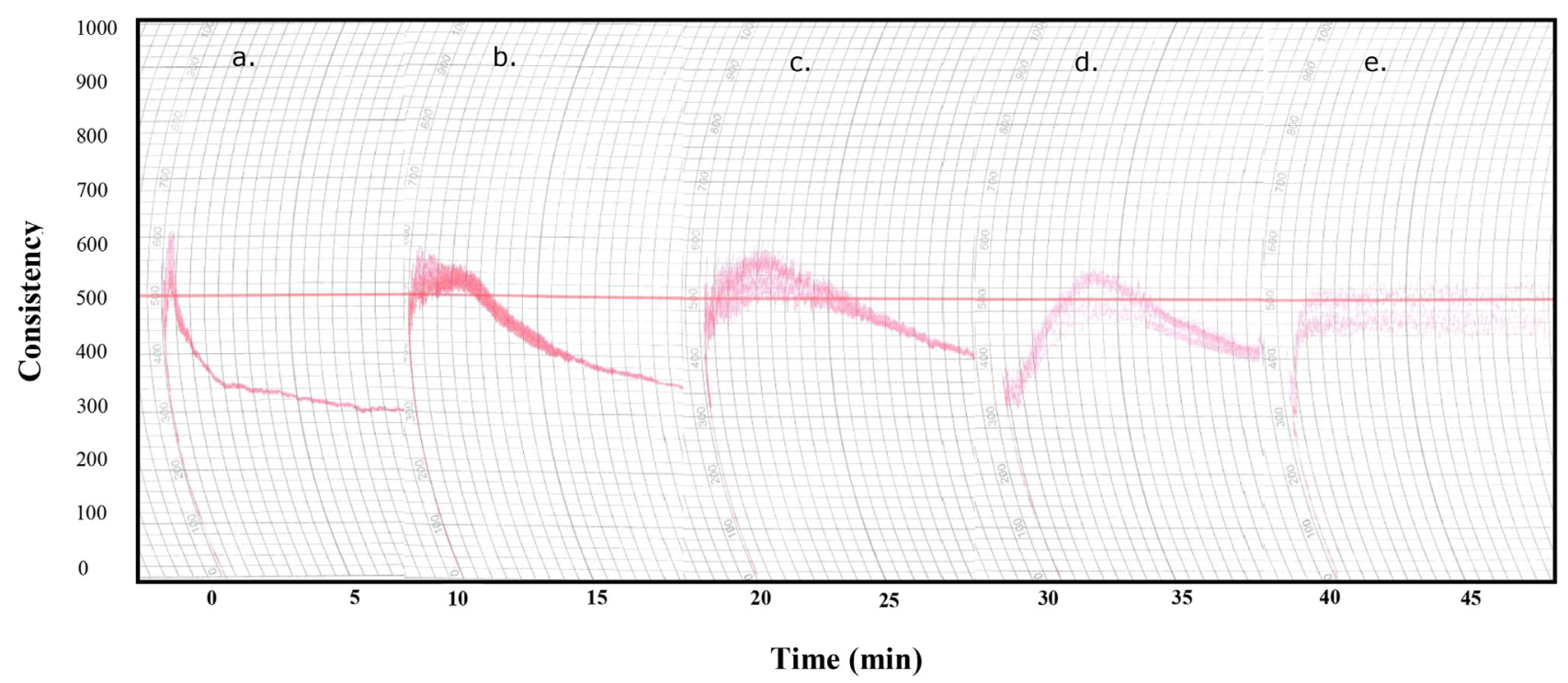

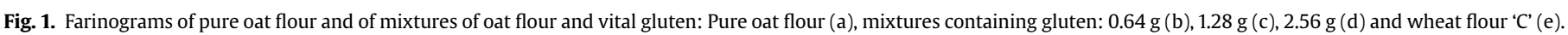

consistencies by adjusting the level of water. Consistency of the dough system was very sensitive to water, peak consistency increased from 500 to $1000 \mathrm{BU}$ with a decrease of $1.2 \mathrm{ml}$ water/10 $\mathrm{g}$ flour mixture. Maximum resistance to extension of the selected dough system increased with consistency while extensibility decreased (Fig. 3). This dough system at a consistency between 900 and $1000 \mathrm{BU}$ had similar extensibility properties to wheat Patent flour at $500 \mathrm{BU}$; therefore, and because the maximum consistency of the Farinograph is $1000 \mathrm{BU}$, a consistency of $900 \mathrm{BU}$ was chosen as standard for the selected oat dough system. The strain hardening of the dough at $500 \mathrm{BU}$ was 1.22 , at $700 \mathrm{BU}$ was 1.17 and at $900 \mathrm{BU}$ was 1.20 .

\subsection{Effect of mixing time on extensibility properties}

To conclude with the standardisation, extensibility properties of the selected dough system, at a consistency of $900 \mathrm{BU}$, were tested after mixing for $2,3,4$, and 5 min. The dough system kept its extensibility properties after mixing for 2 or $3 \mathrm{~min}$, but a decline was observed with longer mixing times (results not shown). As the peak time might vary between cultivars, we decided to use a criterion of peak time plus $1 \mathrm{~min}$.

\subsection{Extensibility properties of ten oat cultivars}

Extensibility properties of ten oat cultivars were evaluated using the standard dough system developed: $1.28 \mathrm{~g}$ gluten plus $8.72 \mathrm{~g}$ oat flour, $900 \mathrm{BU}$ consistency, mixing at peak time plus $1 \mathrm{~min}$. The test

Table 2

Water absorption (flour basis) and strain hardening of oat flour mixtures containing different levels of gluten.

\begin{tabular}{llll}
\hline Gluten content $(\mathrm{g})$ & Water \% & Strain hardening value & $R^{2}$ \\
\hline 0 & 57.7 & 0.73 & 0.89 \\
0.08 & 57.7 & 0.37 & 0.93 \\
0.16 & 58.5 & 0.23 & 0.74 \\
0.32 & 60.0 & 0.76 & 0.99 \\
0.64 & 61.8 & 1.29 & 0.99 \\
1.28 & 66.4 & 1.22 & 0.99 \\
2.56 & 78.7 & 1.40 & 0.99 \\
Wheat flour ' $\mathrm{C}$ ' & 54.6 & 1.39 & 0.99 \\
Wheat Patent flour & 67.0 & 1.35 & 0.99 \\
\hline
\end{tabular}

was sensitive to detect differences among oat cultivars; the largest difference in maximum resistance to extension was $74 \%$ and occurred between cultivars Astor and Gele (Fig. 4). The largest difference detected in extensibility at maximum resistance was $40 \%$ between cultivars Astor and Mansholt (Fig. 4). The average coefficient of variation was $6 \%$. There was no correlation between the two parameters for the group of oat varieties tested, which means that breeding to optimise both may be possible. The results proved that our standard test based on a dough system can be used to detect differences among oat cultivars with respect to technological parameters relevant for dough based bread-making.

\section{Discussion}

In this study, we demonstrated that it is possible to reconstruct the technological properties of wheat flour by using a mixture of oat flour and gluten powder ( $80 \%$ protein), and that reproduction of various wheat flour quality profiles depends on the amount of gluten present in the mixture.

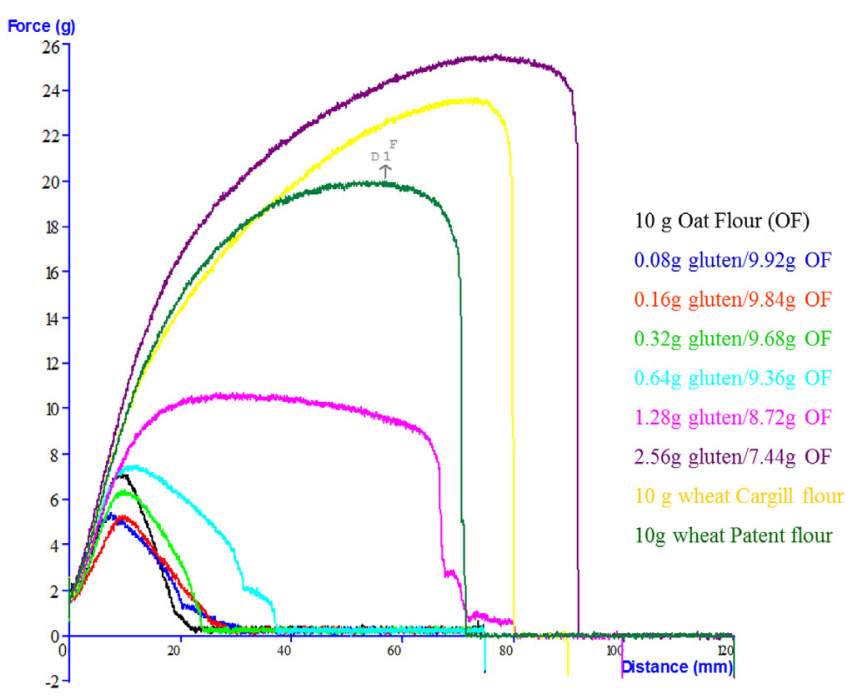

Fig. 2. Resistance to extension (force) and extensibility (distance) of oat flour with a replaced fraction with vital gluten. 


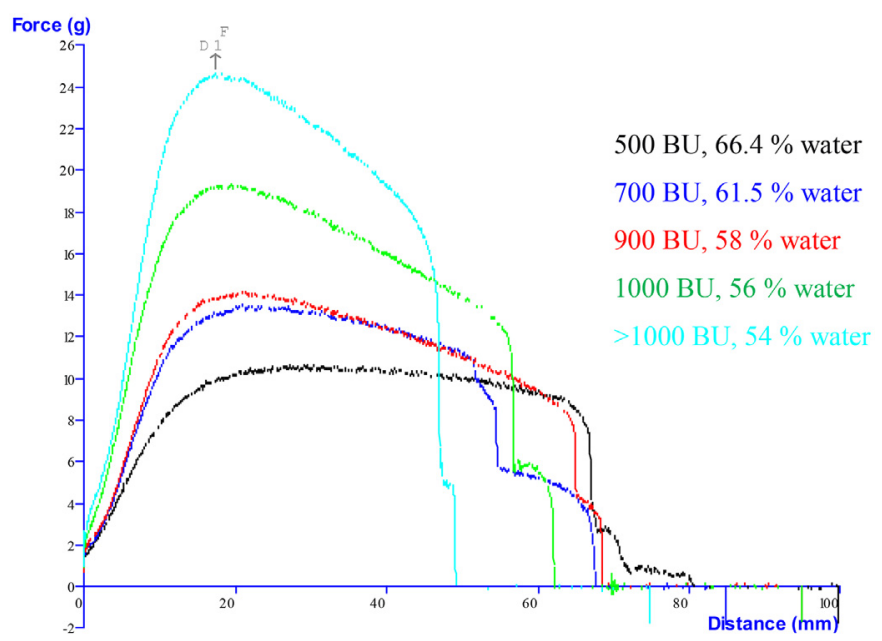

Fig. 3. Maximum force and distance of a selected dough system composed of $8.72 \mathrm{~g}$ oat flour and $1.28 \mathrm{~g}$ gluten at different consistencies.

The reproduction of the extensibility parameters of wheat flour used as a source of gluten at 500 BU consistency -standard for wheat flour-, was achieved with a mixture that contained $25.6 \%$ gluten powder (2.56 g gluten powder/7.44 g oat flour), which is very high in comparison with the gluten content of its counterpart wheat flour (10.4\% protein, from which about $80 \%$ is expected to be gluten (Hamer, 2003)). Reproduction of the extensibility properties of another wheat flour profile -wheat Patent flour-, was possible by decreasing the amount of gluten in the mixture by half, $12.8 \%$ (1.28 g gluten powder/8.72 g oat flour), and by increasing dough consistency from 500 to $900 \mathrm{BU}$. Consistency was very sensitive to water as a small decrease of water already caused a large increase in consistency and a considerable improvement of resistance to extension of the dough, without affecting to a large extent its maximum distance. From this, we conclude that the standard Farinograph consistency of $500 \mathrm{BU}$, used to prepare wheat dough, should not be extrapolated to prepare oat dough.

What people normally call 'oat bread' is in fact a composite bread made of a mixture of oat meal and wheat flour. Mixing oat and wheat flour is done mainly to improve the fiber content and nutritional value of wheat bread with beta-glucans from oats, but some detrimental effects of bran particles, which are also rich in beta-glucans (Table 1), on bread structure have been reported. So far, $51 \%$ is the maximum proportion of whole oat meal used in composite oat/wheat bread in a dough system without compromising textural characteristics (Flander et al., 2007). However, our approach was different and it is important to highlight that our standard dough system was based on a sieved fraction of oat meal $(<0.250 \mathrm{~mm})$. It closely resembled the texture of normal wheat flour, which means that detrimental effects of bran particles were removed (Gan et al., 1992; Noort et al., 2010), but also a large proportion of the beta-glucans (Table 1). Oat flour of similar texture should be used to replicate the results obtained. The fact that we were able to reproduce extensibility properties of wheat flour using oat flour as a base instead of oat meal is novel. We were not able to do this using oat meal (data not shown) suggesting that removal of bran fractions can be a way to improve the textural quality of oat bread. On the other hand, the nutritional quality of oats is also based on the presence of high amounts of beta-glucans. So, any process should try to improve texture while maintaining the highest possible content of beta-glucans.

The standard test presented in this paper was specifically designed with the application of oats in a dough system in mind. So far, differences in bread-making performance of commercial oat flours and of oat cultivars have been reported based on a batter system, and under the same formulation for all cultivars and flours (Hüttner et al., 2010a,b; Hüttner et al., 2011). This approach of using the same amount of water for different flours, implicitly assumes that flours do not differ in their water binding capacity. However, it is known that oat cultivars can strongly differ in the content of water binders: starch, damaged starch, proteins and beta-glucans. Consequently, comparing oat cultivars using the same amount of water for all of them might mask differences in their bread-making potential related to their composition, which is not only affected by the cultivar used to make the flour, but also by the milling process (Gray et al., 2000). Our standard system is developed to make the comparison under the same conditions of Farinograph consistency (all cultivars were compared at $900 \mathrm{BU}$ ), just like it is done for wheat flour (at $500 \mathrm{BU}$ ).

The main purpose of this paper is to present the standard method and demonstrate its sensitivity in a relevant way. We accomplished the goal, as our standard test was sensitive to detect differences among oat cultivars. There can be several explanations for these

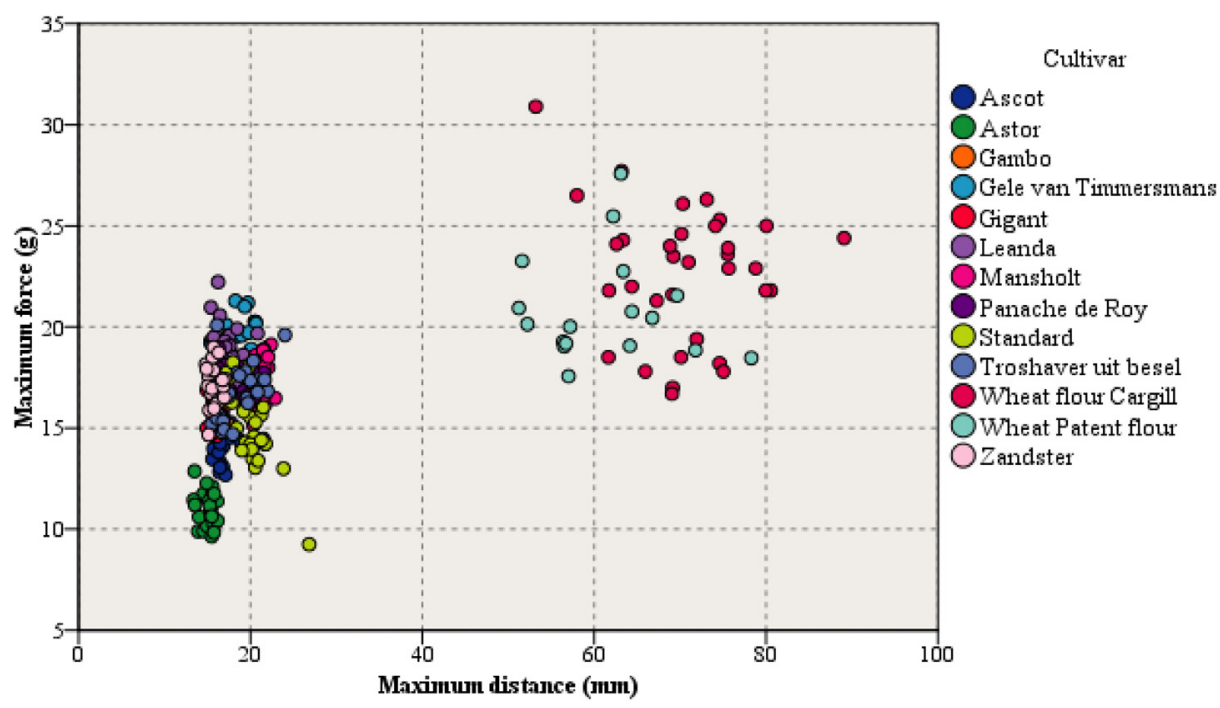

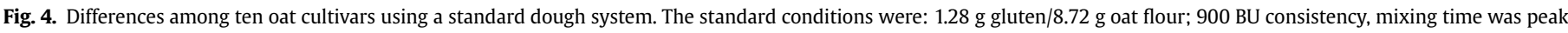
time plus one. 
differences, such as differences in beta-glucan content, protein content and protein composition. However, a comparison of contents and test results does not give a clear correlation, which may be due to the fact that all potentially relevant oat flour components vary from cultivar to cultivar, so that their effect cannot be disentangled. In our opinion this indicates that the effect of the concentration of each of the relevant components needs more thorough follow-up research. Our standard test is only the first step towards oat bread.

\section{Conclusion}

There is a considerable lack of understanding of the effects of differences (both quantitative and qualitative) in oat components in relation to bread making. Oat is either used as an addition to wheatbased dough or in an oat-based batter system. We have produced dough using a mixture of oat flour and vital gluten that had similar extensibility characteristics to a pure wheat dough. This dough forms a sensitive test system to detect differences among oat cultivars and can be used to study the contribution of various oat components (avenins, beta-glucans and oil) to the quality of oat bread.

\section{Acknowledgements}

This research was funded by the Celiac Disease Consortium, an Innovative Cluster approved by the Netherlands Genomics Initiative and partially funded by the Dutch Government (BSIK03009), by the Ministry of Economic Affairs (KB05-001-019, KB05-003-032, KB15-001-007), and The Europees Fonds voor Regionale Ontwikkeling (EFRO), which is supported by the European Union and the province Gelderland. Praktijkonderzoek Plant \& Omgeving (PPO) is thanked for providing the ten oat varieties. Hetty C. Van den Broeck is thanked for beta-glucan measurements.

\section{Appendix A. Supplementary data}

Supplementary data related to this article can be found at http:// dx.doi.org/10.1016/j.jcs.2013.10.007.

\section{References}

Bushuk, W., 1998. Wheat breeding for end-product use (reprinted from wheat: prospects for global improvement, 1998). Euphytica 100, 137-145.
Belitz, H.D., Grosch, W., Schieberle, P., 2004. Cereals and Cereal Products. Food Chemistry, third ed. Springer, Berlin, pp. 673-746.

Butt, M.S., Tahir-Nadeem, M., Khan, M.K.I., Shabir, R., Butt, M.S., 2008. Oat: unique among the cereals. Eur. J. Nutri. 47, 68-79.

Dunnewind, B., Sliwinski, E.L., Grolle, K., Van Vliet, T., 2003. The Kieffer dough and gluten extensibility rig - an experimental evaluation. J. Texture Stud. 34, $537-560$.

Flander, L., Salmenkallio-Marttila, M., Suortti, T., Autio, K., 2007. Optimization of ingredients and baking process for improved wholemeal oat bread quality. LWT - Food Sci. Technol. 40, 860-870.

Gan, Z., Galliard, T., Ellis, P.R., Angold, R.E., Vaughan, J.G., 1992. Effect of the outer bran layers on the loaf volume of wheat bread. J. Cereal Sci. 15, 151-163.

Gray, D.A., Auerbach, R.H., Hill, S., Wang, R., Campbell, G.M., Webb, C., South, J.B., 2000. Enrichment of oat antioxidant activity by dry milling and sieving. J. Cereal Sci. 32, 89-98.

Hager, A.-S., Wolter, A., Czerny, M., Bez, J., Zannini, E., Arendt, E., Czerny, M., 2012 Investigation of product quality, sensory profile and ultrastructure of breads made from a range of commercial gluten-free flours compared to their wheat counterparts. Eur. Food Res. Technol. 235, 333-344.

Hamer, R.J. 2003. Gluten Progress in Biotechnology. Elsevier Science B.V..pp. 87-131

Hüttner, E.K., Bello, F.D., Arendt, E.K., 2010a. Rheological properties and bread making performance of commercial wholegrain oat flours. J. Cereal Sci. 52, 65-71.

Hüttner, E.K., Dal Bello, F., Zannini, E., Titze, J., Beuch, S., Arendt, E.K., 2011. Physicochemical properties of oat varieties and their potential for breadmaking. Cereal Chem. 88, 602-608.

Huttner, E.K., Dal Bello, F., Arendt, E.K., 2010b. Fundamental study on the effect of hydrostatic pressure treatment on the bread-making performance of oat flour. Eur. Food Res. Technol. 230, 827-835.

Huttner, E.K., Dal Bello, F., Poutanen, K., Arendt, E.K., 2009. Fundamental evaluation of the impact of high hydrostatic pressure on oat batters. J. Cereal Sci. 49, 363-370.

Jenkins, A.L., Jenkins, D.J.A., Zdravkovic, U., Wursch, P., Vuksan, V., 2002. Depression of the glycemic index by high levels of beta-glucan fiber in two functional foods tested in type 2 diabetes. Eur. J. Clin. Nutr. 56, 622-628.

Londono, D.M., Van 't Westende, W.P.C., Goryunova, S.V., Salentijn, E.M.J., Van den Broeck, H.C., Van der Meer, I.M., Gilissen, L.J.W.J., Smulders, M.J.M., 2013. Avenin diversity analysis of the genus Avena (oat). Relevance for people with celiac disease. J. Cereal Sci. 58, 170-177.

Moore, M.M., Juga, B., Schober, T.J., Arendt, E.K., 2007. Effect of lactic acid bacteria on properties of gluten-free sourdoughs, batters, and quality and ultrastructure of gluten-free bread. Cereal Chem. 84, 357-364.

Noort, M.W.J., van Haaster, D., Hemery, Y., Schols, H.A., Hamer, R.J., 2010. The effect of particle size of wheat bran fractions on bread quality - evidence for fibreprotein interactions. J. Cereal Sci. 52, 59-64.

Pulido, O., Gillespie, Z., Zarkadas, M., Dubois, S., Vavasour, E., Rashid, M., Switzer, C., Godefroy, B.S., 2009. Introduction of oats in the diet of individuals with celiac disease: a systematic review. Adv. Food Nutri. Res. 57, 235-285.

Renzetti, S., Arendt, E.K., 2009. Effects of oxidase and protease treatments on the breadmaking functionality of a range of gluten-free flours. Eur. Food Res. Technol. 229, 307-317.

Renzetti, S., Courtin, C.M., Delcour, J.A., Arendt, E.K., 2009. Oxidative and proteolytic enzyme preparations as promising improvers for oat bread formulations: rheological, biochemical and microstructural background. Food Chem. 119, 1465-1473. 